\title{
EDITORIAL
}

\section{Primer curso de inteligencia artificial en radiología}

\author{
Sebastián Bravo-Grau ${ }^{1 *}$, Héctor Henríquez².
}

1.Radiólogo. Pontificia Universidad Católica de Chile. Santiago, Chile.

2.Radiólogo. Clínica Santa María, Santiago, Chile.

Durante los días 21 al 24 de abril del presente año 2021, se llevó a cabo el primer curso de inteligencia artificial (IA) en radiología. Este fue en modalidad 100\% virtual. La convocatoria fue de 280 inscritos: médicos radiólogos, tecnólogos médicos, residentes de radiología, alumnos de medicina, médicos, alumnos de postgrado, entre otros.

El programa de cuatro días incluyó 36 conferencias, 9 charlas de la industria y 4 paneles de discusión.

Contó con la presencia de catorce profesores nacionales y ocho profesores internacionales (Katherine Andriole, Paul Chang, Charles Kahn, Michel T Lu, Emmanuel Salinas, David Bates, Felipe Kitamura, Daniel Capurro). La organización fue dirigida por el Dr. Roberto Miranda y los suscritos.

Las charlas se organizaron en cuatro módulos: 1. Justificación y regulación del uso de datos en radiología. 2. Fundamentos básicos de Machine Learning aplicado a radiología. 3. Integración de herramientas de IA al flujo de trabajo. 4. Aplicación de herramientas de IA.

Los contenidos del curso abordaron diferentes áreas relevantes de la IA desde los principios básicos de manera de introducir a los asistentes sin experiencia ni conocimientos previos, manteniendo un eje central en torno al ejercicio práctico de la radiología y las potenciales aplicaciones e impacto del uso de IA.

Durante los cuatro días de curso pudimos presenciar como la IA ha penetrado fuertemente en el quehacer radiológico de países desarrollados, tanto en la práctica diaria radiológica, proyecciones de investigación y en la formación de especialistas.

En nuestro país ya es una realidad la incorporación de soluciones de IA en el flujo de trabajo radiológico y es necesario contar con capacitación de nuestros profesionales para la toma de decisiones en la incorporación de estas nuevas herramientas. En esta línea la educación formal temprana, idealmente desde el pregrado, será un elemento clave para poder alcanzar un nivel de autonomía y buenas prácticas que permita potenciar correctamente el trabajo radiológico con altos estándares de seguridad en la atención de pacientes.

Finalmente, la investigación y desarrollo de IA en imágenes médicas en nuestro país está dando sus primeros pasos y es necesaria para mejorar la adaptación de nuestros problemas locales a las herramientas de IA vigentes.

Como comité organizador, creemos que este primer curso de IA en radiología cumplió el objetivo de acercar la IA a la comunidad radiológica y motivar a los asistentes a aprender más sobre esta disciplina, que se convertirá en una herramienta más de nuestro ejercicio profesional. 